\title{
Beyond Daytime Sleepiness: Medical, Behavioral, Psychiatric, and Sleep Co-morbid Conditions Associated with Pediatric Narcolepsy
}

\author{
Kiran Maski $^{1}$ - Tara Heroux ${ }^{2}$ \\ Published online: 18 February 2016 \\ (C) Springer International Publishing AG 2016
}

\begin{abstract}
Pediatric narcolepsy can be challenging to diagnose and manage given a broad range of co-morbidities only recently described in the literature. These co-morbidities are broad in scope and span medical, psychiatric, and sleep disorders. Such associated conditions highlight potential novel effects of hypocretin deficiency on metabolic and neural functioning. Clinically, medication treatments for narcolepsy have the potential to alter co-morbid symptoms for better or worse and may guide individual treatment plans. Furthermore, sleep physicians may need to ally with other health care providers in endocrinology and psychiatry to optimize the care of pediatric patients with narcolepsy.
\end{abstract}

Keywords Narcolepsy · Children · Co-morbidities · Obesity · Puberty $\cdot$ Schizophrenia $\cdot$ ADHD $\cdot$ REM behavior disorder . Periodic limb movements $\cdot$ Nocturnal sleep disruption

\section{Introduction}

Narcolepsy is a life-long disease characterized by excessive daytime sleepiness, hypnagogic hallucinations, sleep paralysis, and cataplexy due to loss of hypocretin neurons in the

This article is part of the Topical Collection on Sleep in Children

\section{Kiran Maski}

Kiran.maski@childrens.harvard.edu

Tara Heroux

theroux@students.stonehill.edu

1 Harvard Medical School, Boston Children's Hospital, 300 Longwood Ave, Boston, MA 02115, USA

2 Stonehill College, North Easton, MA, USA lateral hypothalamus [1]. Cataplexy is reported in 65-75\% of the patients with narcolepsy $[2,3]$ and distinguishes the condition of narcolepsy with cataplexy (narcolepsy type 1) from narcolepsy without cataplexy (narcolepsy type 2). Narcolepsy is a rare disorder, occurring in $0.025-0.05 \%$ of the population $[4,5]$ with symptoms often developing in the second decade of life between ages 10-19 years of age [4]. Unfortunately, the median time to diagnosis has been reported to be as high as 10.5 years as clinicians frequently fail to recognize narcolepsy symptoms [6]. Part of the problem of this diagnostic delay may be due to general unawareness of narcolepsy presentations [7]. Additionally, pediatric narcolepsy can be of particular diagnostic challenge because of associated medical, sleep, and psychiatric co-morbidities that lead to misdiagnosis. In this article, we highlight co-morbid conditions among children with narcolepsy, discuss possible pathophysiology of these co-morbidities and relationships to hypocretin deficiency, and review clinical diagnostic and management concerns in the care of children with narcolepsy.

\section{Obesity and Precocious Puberty}

\section{Obesity}

Obesity [body mass index (BMI) greater than $97 \%$ ] is commonly reported among children with narcolepsy with a prevalence ranging from $50-74 \%$ and is particularly noted at disease onset $[8 \cdot, 9,10]$. Comparatively, adult patients with narcolepsy have less reported obesity with frequencies closer to $30 \%$ [11]. In one study comparing obese and non-obese children with narcolepsy type 1 , participants did not differ in gender or ethnicity, but overweight/obesity was predicted by younger age at narcolepsy diagnosis [mean age: obese 9.7 years $(+/-2.9)$ and non-obese 12.5 years $(+/-3.4)][8 \bullet]$. 
The impact of obesity among children with narcolepsy has functional implications with higher rates of obstructive sleep apnea (OSA), fatigue, and school absenteeism reported compared to that in non-obese children with narcolepsy [10].

The etiology of increased rates of obesity among children with narcolepsy is still unclear. Given the interaction between hypocretin and food satiety hormones, leptin and ghrelin, recent research has explored endocrinopathies as possible etiology for obesity among patients with narcolepsy $[12,13]$. Leptin is a hormone produced by adipocytes that act as an afferent signal in a negative feedback loop, suppressing food intake and promoting energy expenditure. In the absence of leptin, there is a profound increase in weight gain in both animal and human studies [14]. Ghrelin, on the other hand, acts in the exact opposite, stimulating feeding. Hypocretin is decreased with high leptin levels and increased with increasing ghrelin levels, reflecting hypocretin's role in alertness and motivation for food-seeking behaviors [14]. However, in the setting of hypocretin deficiency, patients have not demonstrated alterations of leptin or ghrelin levels suggesting that only a unidirectional relationship exists $[15,16]$. Alterations in leptin and ghrelin have not been specifically studied in children with narcolepsy. This may be an area of future research interest given that obesity tends to develop close to symptom onset, suggesting that there could be a narrow time frame when metabolic dysfunction is more pronounced.

Likewise, studies evaluating energy expenditure found no significant difference in the basal metabolic rate using indirect calorimetry amongst patients with narcolepsy and controls matched for BMI and age [17]. More recent research has explored if weight gain could be related to distinct feeding behaviors associated with narcolepsy. In one study, $23 \%$ of patients with narcolepsy met criteria for an eating disorder [18]. Specifically, patients displayed higher rates of irresistible food cravings and binge eating behaviors compared to controls. Similarly, sleep-related eating disorder (SRED) has been reported in higher frequencies among patients with narcolepsy type 1 (32\%) compared to those in controls (3\%) [19]. In this condition, recurrent eating behaviors occur after arousal from nocturnal sleep periods, and patients have no recall of the eating behavior [20]. Additionally, patients may have bizarre food choices or even eat potentially toxic substances, have injurious behaviors from cooking, and/or have adverse health consequences from nocturnal eating [20]. Given that hypocretin is thought to influence mesolimbic dopamine signaling, absence of hypocretin could result in dysfunction in reward circuits and consequent daytime and nocturnal impulsive behaviors [21]. On the other hand, there is considerable data showing that sleep disruptions and sleepiness in otherwise healthy subjects are associated with poorer food choices that are higher in caloric density [22] and sugar content [23]. In any case, childhood obesity is associated with a number of well-known long-term metabolic and cardiovascular health consequences, and thus, close monitoring of weight and eating behaviors is important in clinical management of pediatric narcolepsy. More immediately, OSA is associated with obesity development and can contribute to daytime sleepiness. Avoidance of high caloric and carbohydrate-dense in the home, cognitive behavioral therapy for binge eating behaviors, and structured weight loss programs may all be therapeutic options for patients with narcolepsy and obesity.

\section{Precocious Puberty}

Precocious puberty is also commonly reported among pediatric patients with narcolepsy suggesting more global hypothalamic dysfunction. Poli et al. reported that $17 \%$ of children with narcolepsy have precocious puberty and $41 \%$ had signs of accelerated pubertal development [8 $[$. In this study, precocious puberty was defined as the appearance of secondary sexual characteristics before girls or boys reached the ages of 8 or 9 years, respectively, if no lesions were identified on brain MRI, and there was marked elevation of plasma levels of luteinizing hormone (LH) following the stimulation of gonadotropin-releasing hormone $(\mathrm{GnRH})$. The criteria of being categorized as having accelerated pubertal development included advanced bone/age ratio in the wrist (determined by Xray), with at least one of the isolated symptoms of either thelarche or presence of axillary hair. Interestingly, precocious puberty was more prevalent in children diagnosed with narcolepsy compared to obese controls of the same age suggesting a central cause for hormonal changes. Recognizing that precocious puberty could be a secondary symptom of narcolepsy is important as we have seen a few cases of delayed diagnosis of narcolepsy due to patients being told that their excessive daytime sleepiness was due to "growth spurts." Furthermore, evaluating for precocious puberty is critical because there is the potential for early fusion of epiphyseal openings resulting in growth restriction in children with early, rapid pubertal development. Thus, screening for precocious puberty and prompt referral to endocrinology is important in the management of pre-pubertal children with narcolepsy.

\section{Neurobehavioral/Psychiatric Co-morbidities}

\section{ADHD}

Attention deficit hyperactivity disorder (ADHD) is manifest by symptoms of inattention and hyperactivity, impulsivity before the age of 12 years [24]. ADHD symptoms are present at high rates among children with narcolepsy $[25 \bullet, 26]$. A recent 
cross-sectional survey of children under 18 years of age and found that $35.3 \%$ of children with narcolepsy reported ADHD symptoms compared to $4.8 \%$ of control subjects [25•]. It is well known that sleep disturbances, insufficient sleep, and daytime sleepiness can result in poorer executive functioning, memory, inattention, and hyperactivity in children [27-29]; thus, symptoms of ADHD may be expected among children with narcolepsy. Indeed, excessive daytime sleepiness, insomnia, and fatigue scores among children with narcolepsy were all significantly found to be associated with ADHD symptoms in this cross-sectional study [25•]. However, narcolepsy patients' ADHD symptoms were less likely to improve with treatment of stimulant medications even at higher doses suggesting the need for additional academic support such as a 504 plan or individualized education plan. Aside from ADHD symptoms, one smaller study reported high frequencies of general behavior problems among children with narcolepsy that span emotional and conduct difficulties [30]. Certainly, effective screening and management of problematic behaviors, cognitive difficulties as well as ADHD may help children with narcolepsy optimize their academic potential.

\section{Schizophrenia}

Presentation of narcolepsy type 1 combined with schizophrenia is rare occurring in $1-18$ cases in a population of 2 million based on one report [31]. In contrast, another study showed that approximately $10 \%$ of adolescent patients with narcolepsy type 1 developed schizophrenia at an average age of $2.5+/-1.8$ years after narcolepsy symptom onset [32]. Patients with both narcolepsy and schizophrenia in this study were younger than those with narcolepsy alone and had high prevalence of HQB1*03:01/06:02 allele. While schizophrenia may be a potential co-morbidity, it is also possible that use of stimulants, which are commonly used for treatment of daytime sleepiness, can induce psychotic symptoms in narcolepsy patients. Auger et al. reported increased risk of psychosis $(\mathrm{OR}=12)$, alcohol or poly-substance abuse $(\mathrm{OR}=4.3)$, and psychiatric hospitalization $(\mathrm{OR}=3.2)$ among patients with narcolepsy and idiopathic hypersomnia treated with high dose stimulant (defined as dosage $>$ or $=120 \%$ of the maximum recommended by the American Academy of Sleep Medicine Standards of Practice Committee) [33]. Lastly, it is possible that there is a distinct subtype of narcolepsy with psychotic features, a claim which thus far has only been suggested by case reports [34]. AntiNMDA receptor antibodies have been detected in patients with narcolepsy with psychotic features (with and without encephalitis symptoms) suggesting autoimmune etiology may result in more broad neuropsychiatric symptoms [35]. Of great concern is that narcolepsy could be misdiagnosed as schizophrenia based on reports of hallucinations. While hallucinations are experienced in both narcolepsy and schizophrenia, the hallucinations experienced by patients with narcolepsy are almost always associated with sleep onset/offset (hypnagogic/hypnopompic hallucinations) and more likely to be multimodal in presentation (visual and tactile) [36].

\section{Primary Mood Disorders}

In both adults and children, primary mood disorders are reported in up to $1 / 3$ of patients with narcolepsy and range from depression, general anxiety, obsessive compulsive disorder, and social phobia [37]. Among children with narcolepsy, $25 \%$ of patients reported depressive symptoms on the Children's Depression Inventory [38 $]$. Symptom burden tended to be higher in those reporting depression with more frequent hypnogogic hallucinations and sleep paralysis, higher subjective sleepiness scores, and longer duration of symptoms before diagnosis compared to those in non-depressive patients. However, depressive feelings were not significantly better between those patients treated with stimulants for daytime sleepiness or venlafaxine for cataplexy. These high rates of depression among patients with narcolepsy may suggest that mood disorder is intrinsic to the narcolepsy diagnosis. The sleep architecture of depressive patients without narcolepsy has been reported to include short rapid eye movement (REM) onset latency, increased REM pressure with sleep onset REM periods, and sleep fragmentationall findings similar to those reported in patients with narcolepsy. Hypocretin deficiency induces cholinergicmonoaminergic imbalance with primary effect on alertness but such dysregulation has been shown to directly influence mood as well [39]. In hypocretin-2 null mice that had pharmacologic inhibition of hypocretin receptor 2 signaling, an increase in despair behavior was noted but similar behavior was not noted in hypocretin-1 null mice [40]. Furthermore, recent research has highlighted the role of REM sleep in affective reactivity and emotional information processing. For instance, REM sleep seems to be specifically involved in emotional memory and appears to facilitate the consolidation of memories with negative valence [41, 42]. This model may suggest that pathological increases in REM sleep as seen in narcolepsy may amplify the strength of negative memories and predispose patients to mood disorders. Clinically, screening for affective problems among patients with narcolepsy is important as medications used to treat core symptoms such as stimulants may worsen underlying mood disorder symptoms. While treatment of depressive symptoms and cataplexy often involve use of selective serotonin reuptake inhibitors (SSRIs) or serotonin-norepinephrine reuptake 
inhibitors (SNRIs), depressive symptoms are still reported among those with treated cataplexy [38•]. Ultimately, allying with mental health providers is necessary for assessment and management of psychological health.

\section{Sleep-Related Co-morbidities}

Patients with narcolepsy have a host of co-morbid sleep dysfunction and disorders that have become almost pathognomonic of this disease condition. In our clinical experience, sometimes, these associated sleep disorders are misdiagnosed as the primary conditions, and the diagnosis and treatment of narcolepsy is delayed. NREM parasomnias, REM parasomnias, OSA as well as nocturnal movement disorders are all commonly reported among narcolepsy patients [43, 44]. In our experience, these findings on a sleep study have resulted in misdiagnosis of another primary sleep disorder (Fig. 1). The conditions of disrupted nocturnal sleep, periodic limb movements of sleep, and REM parasomnias are highlighted below.

\section{Disrupted Nighttime Sleep}

The prevalence of findings of disrupted nighttime sleep ranges between 30-95\% among patients with narcolepsy and is considered a supporting feature of narcolepsy diagnosis [20]. This sleep pattern is best characterized as frequent, brief nightly awakenings and associated poor sleep quality [45]. On polysomnography, these frequent awakening/arousals occur after sleep onset, more in stage 1 NREM sleep, and there are more frequent shifts to stage 1 NREM sleep or wake from deeper sleep stages [45]. This pattern of sleep fragmentation with high number of brief wakings has also been noted among children with narcolepsy and is a distinguishing feature from other hypersomnia conditions [46]. This disrupted nocturnal sleep pattern is distinct from insomnia in which patients report inability to fall asleep and stay asleep during the night resulting in prolonged waking periods. In contrast, patients with narcolepsy fall asleep rapidly and have frequent arousals or brief waking periods but generally return quickly to sleep $[47,48]$.

\section{Periodic Limb Movements of Sleep and REM Behavior Disorder}

Increased motor activity during the sleep period is also commonly reported among patients with narcolepsy, giving sleep a restless appearance and possibly contributing to disrupted nocturnal sleep patterns. The mean motor activity index, defined as movement episodes per hour of sleep excluding chin or tibialis anterior electromyographic-related muscle activity, was 59.9/h in sleep in patients with narcolepsy type $1 \mathrm{com}$ pared to $15.4 / \mathrm{h}$ among healthy controls $(p=0.004)$ [49]. Underlying these increased movements may be downstream dopaminergic abnormalities mediated by hypocretin deficiency though there is animal data suggesting dysfunctions of the glycinergic/GABA premotor neurons located in the medullary

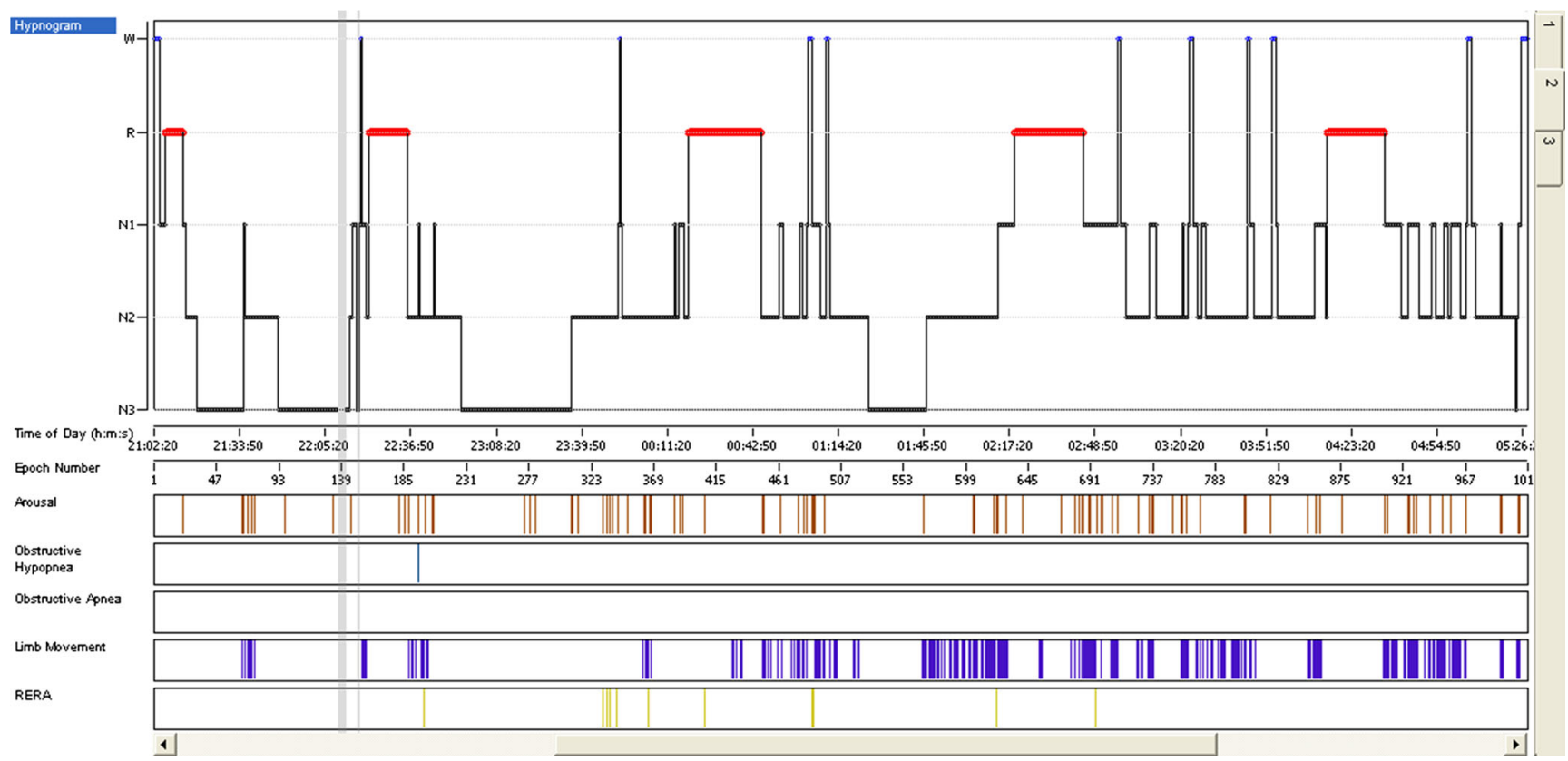

Fig. 1 A hypnogram of an 11-year-old patient with narcolepsy type 1 initially misdiagnosed with periodic limb movements (periodic limb movements index of $25 / \mathrm{h}$ ). REM periods are red capped peaks. Note the patient has a nocturnal sleep onset REM period (REM latency
$<15 \mathrm{~min}$ ) which is specific to narcolepsy type 1 . These findings suggest a primary diagnosis of narcolepsy type 1 with co-morbid periodic limb movements of sleep 
ventral gigantocellular reticular nucleus that may also be at play $[50,51]$.

More recently, the sleep disorders of periodic limb movements of sleep and REM behavior disorder (REM parasomnias) have been highlighted in the recent narcolepsy literature. Periodic limb movements of sleep (PLMS) refers to a movement disorder that presents as rhythmic, repetitive myoclonic-like jerking of the limbs that disturb sleep [20]. PLMS has been reported in up to $75 \%$ of patients with narcolepsy, often with higher indexes of movements per hour $(>15 / \mathrm{h})$ compared to controls [43, 44]. Similarly, REM behavior disorder which requires repeated episodes of dream enactment with sleep-related vocalization and/or complex motor behavior with polysomnographic evidence of REM without atonia is frequently reported. In one survey of patients with narcolepsy, $36 \%$ reported symptoms consistent with REM behavior disorder [52] but more recent data has highlighted much higher rates of polysomnographic findings of REM without atonia [44]. REM without atonia reflects excessive amount of sustained or intermittent elevation of tonic submental tone or excessive phasic activity (which clinically may look like twitching in REM sleep) [53]. In children, REM behavior disorder (RBD) may present with symptoms of yelling, flailing limbs, pantomimic behaviors, gestures as well as more violent actions such a punching and kicking commonly reported among adults with RBD [54]. In children, findings of PLMS with indexes of $>5 / \mathrm{h}$ are not uncommon on PSG with rates of $7.7 \%$ among community recruited participants [55], but RBD and REM without atonia are relatively rare in this population [56]. Thus, the finding of both these conditions together could be supportive of the diagnosis of narcolepsy [57] though larger studies are needed for verification. Given that REM without atonia is a cardinal feature of REM behavior disorder, close screening of dream enactment is clinically necessary. Furthermore, use of SSRIs commonly used for the treatment of narcolepsy may unmask symptoms of RBD [58] and result in more deregulated sleep quality and daytime sleepiness of patients.

\section{Conclusion}

Recent research in pediatric narcolepsy has highlighted associated with medical, psychiatric, and sleep co-morbidities. These co-morbidities can often delay diagnosis of narcolepsy when interpreted as primary conditions [49]. Furthermore, such co-morbid conditions can add to the challenge of managing primary narcolepsy symptoms as in the case of stimulants used for daytime sleepiness treatment worsening associated anxiety. Furthermore, the broad range of co-morbidities associated with narcolepsy highlight the need of a multidisciplinary management approach that may involve health care providers in endocrinology and psychiatry as well as sleep medicine. Longitudinal studies on pediatric narcolepsy are needed to better assess the progression of these comorbidities and study effectiveness and complications of treatment on primary and secondary disease symptoms.

\section{Compliance with Ethical Standards}

Conflict of Interest Kiran Maski receives research support from Jazz Pharmaceuticals, Inc, as the site PI for the sodium oxybate clinical trial in children with narcolepsy type 1 and has received funds from Medscape Inc. to be a speaker on a CME lecture on pediatric narcolepsy.

Tara Heroux has no dislcosures.

Human and Animal Rights and Informed Consent This article does not contain any studies with human or animal subjects performed by any of the authors.

\section{References}

Papers of particular interest, published recently, have been highlighted as:

- Of importance

1. Nishino S, Ripley B, Overeem S, Lammers GJ, Mignot E. Hypocretin (orexin) deficiency in human narcolepsy. Lancet. 2000;355(9197):39-40.

2. Dauvilliers Y, Billiard M, Montplaisir J. Clinical aspects and pathophysiology of narcolepsy. Clinical neurophysiology: official journal of the International Federation of Clinical Neurophysiology. 2003;114(11):2000-17.

3. Overeem S, Mignot E, van Dijk JG, Lammers GJ. Narcolepsy: clinical features, new pathophysiologic insights, and future perspectives. Journal of clinical neurophysiology: official publication of the American Electroencephalographic Society. 2001;18(2):78105.

4. Silber MH, Krahn LE, Olson EJ, Pankratz VS. The epidemiology of narcolepsy in Olmsted County, Minnesota: a population-based study. Sleep. 2002;25(2):197-202.

5. Longstreth Jr WT, Koepsell TD, Ton TG, Hendrickson AF, van Belle G. The epidemiology of narcolepsy. Sleep. 2007;30(1):1326.

6. Morrish E, King MA, Smith IE, Shneerson JM. Factors associated with a delay in the diagnosis of narcolepsy. Sleep Med. 2004;5(1): $37-41$.

7. Thorpy MJ, Krieger AC. Delayed diagnosis of narcolepsy: characterization and impact. Sleep medicine. 2014;15(5):502-7.

8. Poli F, Pizza F, Mignot E, Ferri R, Pagotto U, Taheri S, et al. High prevalence of precocious puberty and obesity in childhood narcolepsy with cataplexy. Sleep. 2013;36(2):175-81. Highlights high rate of obesity and precocious puberty in a chart of pediatric patients with narcolepsy. The study also investigates differences in the metabolic profiles of obese children with narcolepsy compared to non-narcolepsy obese patients.

9. Kotagal S, Krahn LE, Slocumb N. A putative link between childhood narcolepsy and obesity. Sleep medicine. 2004;5(2):147-50.

10. Inocente CO, Lavault S, Lecendreux M, Dauvilliers Y, Reimao R, Gustin MP, et al. Impact of obesity in children with narcolepsy. CNS neuroscience \& therapeutics. 2013;19(7):521-8. 
11. Schuld A, Hebebrand J, Geller F, Pollmacher T. Increased bodymass index in patients with narcolepsy. Lancet. 2000;355(9211): 1274-5.

12. Yamanaka A, Beuckmann CT, Willie JT, Hara J, Tsujino N, Mieda $\mathrm{M}$, et al. Hypothalamic hypocretin neurons regulate arousal according to energy balance in mice. Neuron. 2003;38(5):701-13.

13. Burdakov D, Gerasimenko O, Verkhratsky A. Physiological changes in glucose differentially modulate the excitability of hypothalamic melanin-concentrating hormone and hypocretin neurons in situ. The journal of neuroscience: the official journal of the Society for Neuroscience. 2005;25(9):2429-33.

14. Kok SW, Meinders AE, Overeem S, Lammers GJ, Roelfsema F, Frolich M, et al. Reduction of plasma leptin levels and loss of its circadian rhythmicity in hypocretin (orexin)-deficient narcoleptic humans. The journal of clinical endocrinology and metabolism. 2002;87(2):805-9.

15. Donjacour CE, Pardi D, Aziz NA, Frolich M, Roelfsema F, Overeem S, et al. Plasma total ghrelin and leptin levels in human narcolepsy and matched healthy controls: basal concentrations and response to sodium oxybate. Journal of Clinical Sleep Medicine: JCSM: official publication of the American Academy of Sleep Medicine. 2013;9(8):797-803.

16. Arnulf I, Lin L, Zhang J, Russell IJ, Ripley B, Einen M, et al. CSF versus serum leptin in narcolepsy: is there an effect of hypocretin deficiency? Sleep. 2006;29(8):1017-24.

17. Dahmen N, Tonn P, Messroghli L, Ghezel-Ahmadi D, Engel A. Basal metabolic rate in narcoleptic patients. Sleep. 2009;32(7):962-4.

18. Fortuyn HA, Swinkels S, Buitelaar J, Renier WO, Furer JW, Rijnders $\mathrm{CA}$, et al. High prevalence of eating disorders in narcolepsy with cataplexy: a case-control study. Sleep. 2008;31(3):335-41.

19. Palaia V, Poli F, Pizza F, Antelmi E, Franceschini C, Moghadam $\mathrm{KK}$, et al. Narcolepsy with cataplexy associated with nocturnal compulsive behaviors: a case-control study. Sleep. 2011;34(10): 1365-71.

20. American Academy of Sleep Medicine: international classification of sleep disorders, 3rd ed. Darien, IL: American Academy of Sleep Medicine; 2014.

21. Calipari ES, Espana RA. Hypocretin/orexin regulation of dopamine signaling: implications for reward and reinforcement mechanisms. Frontiers in behavioral neuroscience. 2012;6:54.

22. Depner CM, Stothard ER, Wright Jr KP. Metabolic consequences of sleep and circadian disorders. Current diabetes reports. 2014;14(7):507.

23. Hjorth MF, Quist JS, Andersen R, Michaelsen KF, Tetens I, Astrup $\mathrm{A}$, et al. Change in sleep duration and proposed dietary risk factors for obesity in Danish school children. Pediatric obesity. 2014;9(6): e156-159.

24. American Psychiatric Association. Diagnostic and statistical manual of mental disorders. 5th ed. Arlington: American Psychiatric Publishing; 2013.

25. Lecendreux M, Lavault S, Lopez R, Inocente CO, Konofal E, Cortese $\mathrm{S}$, et al. Attention-deficit/hyperactivity disorder (ADHD) symptoms in pediatric narcolepsy: a cross-sectional study. Sleep. 2015;38(8):1285-95. Large cross sectional study showing high rates of ADHD symptoms among children with narcolepsy and that these patients tend to have treatment resistant ADHD symptoms.

26. Modestino EJ, Winchester J. A retrospective survey of childhood ADHD symptomatology among adult narcoleptics. Journal of attention disorders. 2013;17(7):574-82.

27. Millman RP, Working Group on Sleepiness in Adolescents/Young Adults, AAP Committee on Adolescence. Excessive sleepiness in adolescents and young adults: causes, consequences, and treatment strategies. Pediatrics. 2005;115(6):1774-86.

28. Cortese S, Konofal E, Yateman N, Mouren MC, Lecendreux M. Sleep and alertness in children with attention-deficit/hyperactivity disorder: a systematic review of the literature. Sleep. 2006;29(4): 504-11.

29. O'Brien LM. The neurocognitive effects of sleep disruption in children and adolescents. Child and adolescent psychiatric clinics of North America. 2009;18(4):813-23.

30. Posar A, Pizza F, Parmeggiani A, Plazzi G. Neuropsychological findings in childhood narcolepsy. Journal of child neurology. 2014;29(10):1370-6.

31. Kadasah S, Arfin M, Tariq M. HLA-DRB1 association with schizophrenia in Saudi Arabian patients. International journal of psychiatry in clinical practice. 2011;15(2):112-7.

32. Huang YS, Guilleminault C, Chen CH, Lai PC, Hwang FM. Narcolepsy-cataplexy and schizophrenia in adolescents. Sleep medicine. 2014;15(1):15-22.

33. Auger RR, Goodman SH, Silber MH, Krahn LE, Pankratz VS, Slocumb NL. Risks of high-dose stimulants in the treatment of disorders of excessive somnolence: a case-control study. Sleep. 2005;28(6):667-72.

34. Melamed Y, Daliahu Y, Paleacu D. Narcolepsy and psychotic states - a case report. The Israel journal of psychiatry and related sciences. 2009;46(1):70-3.

35. Tsutsui K, Kanbayashi T, Tanaka K, Boku S, Ito W, Tokunaga J, et al. Anti-NMDA-receptor antibody detected in encephalitis, schizophrenia, and narcolepsy with psychotic features. BMC psychiatry. 2012;12:37

36. Plazzi G, Fabbri C, Pizza F, Serretti A. Schizophrenia-like symptoms in narcolepsy type 1: shared and distinctive clinical characteristics. Neuropsychobiology. 2015;71(4):218-24.

37. Fortuyn HA, Lappenschaar MA, Furer JW, Hodiamont PP, Rijnders CA, Renier WO, et al. Anxiety and mood disorders in narcolepsy: a case-control study. General hospital psychiatry. 2010;32(1):49-56.

38. Inocente CO, Gustin MP, Lavault S, Guignard-Perret A, Raoux A, Christol N, et al. Depressive feelings in children with narcolepsy. Sleep medicine. 2014;15(3):309-14. Article highlights high rate of depressive symptoms among pediatric patients with narcolepsy.

39. Janowsky DS, el-Yousef MK, Davis JM, Sekerke HJ. A cholinergic-adrenergic hypothesis of mania and depression. Lancet. 1972;2(7778):632-5.

40. Scott MM, Marcus JN, Pettersen A, Birnbaum SG, Mochizuki T, Scammell TE, et al. Hcrtr1 and 2 signaling differentially regulates depression-like behaviors. Behavioural brain research. 2011;222(2):289-94.

41. Nishida M, Pearsall J, Buckner RL, Walker MP. REM sleep, prefrontal theta, and the consolidation of human emotional memory. Cerebral cortex. 2009;19(5):1158-66.

42. Hu P, Stylos-Allan M, Walker MP. Sleep facilitates consolidation of emotional declarative memory. Psychological science. 2006;17(10):891-8.

43. Sasai-Sakuma T, Kinoshita A, Inoue Y. Polysomnographic assessment of sleep comorbidities in drug-naive narcolepsy-spectrum disorders - a Japanese cross-sectional study. PloS one. 2015;10(8): e0136988.

44. Frauscher B, Ehrmann L, Mitterling T, Gabelia D, Gschliesser V, Brandauer E, et al. Delayed diagnosis, range of severity, and multiple sleep comorbidities: a clinical and polysomnographic analysis of 100 patients of the Innsbruck narcolepsy cohort. Journal of clinical sleep medicine: JCSM: official publication of the American Academy of Sleep Medicine. 2013;9(8):805-12.

45. Roth T, Dauvilliers Y, Mignot E, Montplaisir J, Paul J, Swick T, et al. Disrupted nighttime sleep in narcolepsy. Journal of clinical sleep medicine: JCSM: official publication of the American Academy of Sleep Medicine. 2013;9(9):955-65.

46. Reiter J, Katz E, Scammell TE, Maski K. Usefulness of a nocturnal SOREMP for diagnosing narcolepsy with cataplexy in a pediatric population. Sleep. 2015;38(6):859-65. 
47. Sanchez-Ortuno MM, Carney CE, Edinger JD, Wyatt JK, Harris A. Moving beyond average values: assessing the night-to-night instability of sleep and arousal in DSM-IV-TR insomnia subtypes. Sleep. 2011;34(4):531-9.

48. Rosenthal LD, Merlotti L, Young DK, Zorick FJ, Wittig RM, Roehrs TA, et al. Subjective and polysomnographic characteristics of patients diagnosed with narcolepsy. General hospital psychiatry. 1990;12(3):191-7.

49. Frauscher B, Gschliesser V, Brandauer E, Schonwald SV, Falkenstetter T, Ehrmann L, et al. Motor disturbances during non-REM and REM sleep in narcolepsy-cataplexy: a video-polysomnographic analysis. Journal of sleep research. 2011;20(4):514-21.

50. Brooks PL, Peever JH. Impaired GABA and glycine transmission triggers cardinal features of rapid eye movement sleep behavior disorder in mice. The journal of neuroscience: the official journal of the Society for Neuroscience. 2011;31(19):7111-21.

51. Peever J. Control of motoneuron function and muscle tone during REM sleep, REM sleep behavior disorder and cataplexy/narcolepsy. Archives italiennes de biologie. 2011;149(4):454-66.

52. Nightingale S, Orgill JC, Ebrahim IO, de Lacy SF, Agrawal S, Williams AJ. The association between narcolepsy and REM behavior disorder (RBD). Sleep medicine. 2005;6(3):253-8.
53. Iber-Ancoli S, Chesson A, Quan S. The AASM manual for the scoring of sleep and associated events: rules, terminology and technical specifications. Westchester: American Academy of Sleep Medicine; 2007.

54. Kotagal S. Rapid eye movement sleep behavior disorder during childhood. Sleep medicine clinics. 2015;10(2):163-7.

55. Marcus CL, Traylor J, Gallagher PR, Brooks LJ, Huang J, Koren D, et al. Prevalence of periodic limb movements during sleep in normal children. Sleep. 2014;37(8):1349-52.

56. Lloyd R, Tippmann-Peikert M, Slocumb N, Kotagal S. Characteristics of REM sleep behavior disorder in childhood. Journal of clinical sleep medicine: JCSM: official publication of the American Academy of Sleep Medicine. 2012;8(2):12731.

57. Dauvilliers Y, Rompre S, Gagnon JF, Vendette M, Petit D, Montplaisir J. REM sleep characteristics in narcolepsy and REM sleep behavior disorder. Sleep. 2007;30(7):844-9.

58. Schenck CH, Mahowald MW, Kim SW, O'Connor KA, Hurwitz TD. Prominent eye movements during NREM sleep and REM sleep behavior disorder associated with fluoxetine treatment of depression and obsessive-compulsive disorder. Sleep. 1992;15(3): 226-35. 